\title{
THE JCOMM IN SITU OBSERVING PROGRAMME SUPPORT CENTRE: A DECADE OF PROGRESS AND REMAINING CHALLENGES
}

\author{
Mathieu Belbeoch $^{(1)}$, Hester Viola ${ }^{(1)}$, Howard Freeland ${ }^{(2)}$, Candyce Clark $^{(3)}$, \\ David Meldrum $^{(4)}$, Etienne Charpentier ${ }^{(5)}$, Keith Alverson ${ }^{(6)}$, Peter Dexter ${ }^{(7)}$, \\ Jean-Louis Fellous ${ }^{(8)}$
}

(1) Technical Coordinator, (Joint World Meteorological Organisation (WMO)/Intergovernmental Oceanographic Commission (IOC) Technical Commission for Oceanography and Marine Meteorology) Observing Platform Support Centre), Parc Technologique du Canal, 8-10 rue Hermès, 31526 Ramonville, St Agne, France,

Email: belbeoch@jcommops.org; viola@jcommops.org

(2) Co-chair Argo Steering Team, Institute of Ocean Sciences, 9860 West Saanich Road, PO Box 6000, Sidney V8L 4B2, B.C., Canada, Email: Howard.Freeland@dfo-mpo.gc.ca

(3) NOAA (National Oceanic and Atmospheric Administration/Climate Program Office (CPO), Climate Observation Division, 1100 Wayne Avenue, suite 1202, Silver Spring MD 20910, United States, Email: candyce.clark@noaa.gov

(4) Chair, DBCP and Leader, Technology Development, Scottish Association for Marine Science, Dunstaffnage Marine Laboratory, OBAN PA37 1QA, United Kingdom, Email: dtm@sams.ac.uk

(5) Observing Systems Division, Observing and Information Systems Department, World Meteorological Organization, 7 bis, Avenue de la Paix, Case postale No 2300, CH-1211 Geneva 2, Switzerland, Email: echarpentier@wmo.int

(6) Head of Section, Ocean Observations and Services, Intergovernmental Oceanographic Commission of UNESCO (United Nations Educational, Scientific and Cultural Organisation),

1 rue Miollis, 75732 Paris cedex 15, France, Email: k.alverson@unesco.org

(7) Co-president of (Joint World Meteorological Organisation (WMO)/Intergovernmental Oceanographic Commission (IOC) Technical Commission for Oceanography and Marine Meteorology), Ocean Services Section, Bureau of Meteorology, GPO Box 1289, Melbourne VIC 3001, Australia, Email: p.dexter@bom.gov.au

(8) Co-president of JCOMM (Joint World Meteorological Organisation (WMO)/Intergovernmental Oceanographic Commission (IOC) Technical Commission for Oceanography and Marine Meteorology), Committee on Space Research, (COSPAR), clo CNES (Centre National d'Études Spatiales), 2 Place Maurice-Quentin, 75039 Paris Cedex 01, France, Email: Jean-Louis.Fellous@cosparhq.cnes.fr

\section{DESCRIPTION}

This community white paper will present the origins, evolution and future challenges of JCOMMOPS, the Joint WMO-IOC (World Meteorological Organization/Intergovernmental Oceanographic Commission) Technical Commission for Oceanography and Marine Meteorology (JCOMM) Observing Platform Support Centre.

JCOMMOPS follows the direction of international panels and steering teams. It is a component of the international coordination mechanism, which aims on behalf of JCOMM to:

- assist as appropriate in the implementation of the Global Ocean Observing System;

- develop synergies between observing systems;

- assist in the planning, implementation and operations of the observing systems;

- monitor and evaluate the performance of the networks;

- encourage cooperation between communities and member states;

- encourage data sharing;
- assist in data distribution on the Internet and GTS (Global Telecommunications System);

- relay users' feedback on data quality to platform operators;

- encourage harmonisation of data and instrumentation related practices;

- provide technical assistance and user support worldwide;

- act as a clearing house and focal point for all aspects of the program.

\section{BACKGROUND}

The main global in situ Ocean observation networks are implemented nationally, however they do address the needs of international applications and requirements, and cooperate via organizations such as the World Meteorological Organization (WMO) and the Intergovernmental Oceanographic Commission (IOC) of UNESCO (United Nations Educational Scientific and Cultural Organization). This cooperation is essential to ensure the networks are as efficient as possible. Such cooperation occurs, organizationally through the Global Ocean Observing System (GOOS), 
the Global Climate Observing System (GCOS) both sponsored by WMO, IOC, UNEP (United Nations Environment Programme) and ICSU (International Council of Scientific Unions), and the Joint WMO-IOC Commission for Oceanography and Marine Meteorology (JCOMM). It also occurs through interactions between funding agencies, program managers or principal investigators, platform operators, satellite data telecommunication providers, instrument manufacturers, data centres, and operational and research data users. JCOMMOPS represents a bridge between the oceanographic and meteorological communities and keeps the day-to-day link with the platform operators and all of the actors involved in such programs.

Building upon the experience of the Data Buoy Cooperation Panel (DBCP), which has had a Technical Coordinator since 1987, and on the Argo Information Centre (shaped during the OceanObs'99 symposium), JCOMMOPS, which was formally established by the first Session of JCOMM in 2001, has gradually progressed towards being a near-operational support centre. JCOMMOPS comprises two Technical Coordinators, now supporting DBCP, Argo, the JCOMM Ship Observations Team, which includes the SOOP (Ship of Opportunity Program) Implementation Panel (IP), Voluntary Observing Ship (VOS) Panel, as well as the Ocean Sustained Interdisciplinary Timeseries Environment observation System (OceanSITES).

JCOMMOPS now therefore supports the implementation of a number of different types of in situ observing systems including:

- Drifting and moored buoys in the high seas and tropical moorings (DBCP);

- XBTs (Expendable Bathythermographs), TSGs, atmospheric soundings from ships, meteorological observations from ships (SOT (JCOMM Ship Observations Team));

- Profiling floats (Argo);

- Deep ocean time-series reference stations using Moorings, cables, gliders and other platforms. (OceanSITES).

Each program is quite different but there are many common issues to address in terms of program implementation (e.g. opportunities for the deployment of instruments at sea, platform/instrument metadata management (information system development), international relations and cooperative agreements, liaison with IOC and WMO). Each of the two Technical Coordinators focuses on their own $\operatorname{program}(\mathrm{s})$ and its individual requirements, but they also work together when considering higher level issues impacting the implementation of more than one program. JCOMMOPS shares a common technical infrastructure, develops tools across programs, share ideas, and because of that the Technical Coordinators produce more together, for their programs, than they would if they worked independently.

JCOMMOPS is now facing a number of challenges, including finding the best ways to integrate the services it is providing across all programs, improving the usability and reliability of the information system and web services, and supporting new programs within JCOMM. JCOMM plans to expand the scope of JCOMMOPS to become an Observing Program Support Centre and provide additional support to programs such as the IOC International Ocean Carbon Coordination Project (IOCCP), and the Global Sealevel Observing System (GLOSS).

See Figure 1 for details.

\subsection{Chronology:}

1987 to 1989

- The first DBCP Technical Coordinator (TC) (David Meldrum), Toulouse France, Argos.

1989 to 1993

- The second TC DBCP recruited (Etienne Charpentier), Largo, USA, Argos.

1993 to 1998

- DBCP TC position moved to France (Toulouse, CLS Argos).

1998 to 2001

- DBCP TC also acting as SOOPIP TC.

- Proposal informally discussed at OceanObs'99 for establishing an Argo Information Centre (AIC) that would particularly address implementation of IOC Resolution XX-6 requesting notification for floats that might drift into Member States Exclusives Economic Zones.

- Argo Steering Team agreed at its second meeting (Southampton, March 2000) to establish AIC and host it in Toulouse together with the DBCP/SOOPIP TC.

2001 to Feb 2006

- First Argo TC (Mathieu Belbeoch) recruited and establishment of the Argo Information Centre as part of an embryo JCOMMOPS.

- JCOMMOPS developments effectively started.

- JCOMM-I formally established JCOMMOPS.

- Proposal to JCOMM-II for SOOP (Ship-OfOpportunity Programme) coordination to be expanded to the Ship Observation Team SOT: including SOOPIP (Implementation Panel), VOS 
(Volunteer Observing Ship) \& ASAPP (Automated Shipboard Aerological Programme), (Halifax, Sept.
2005), and to include the collection of information on satellite data requirements.

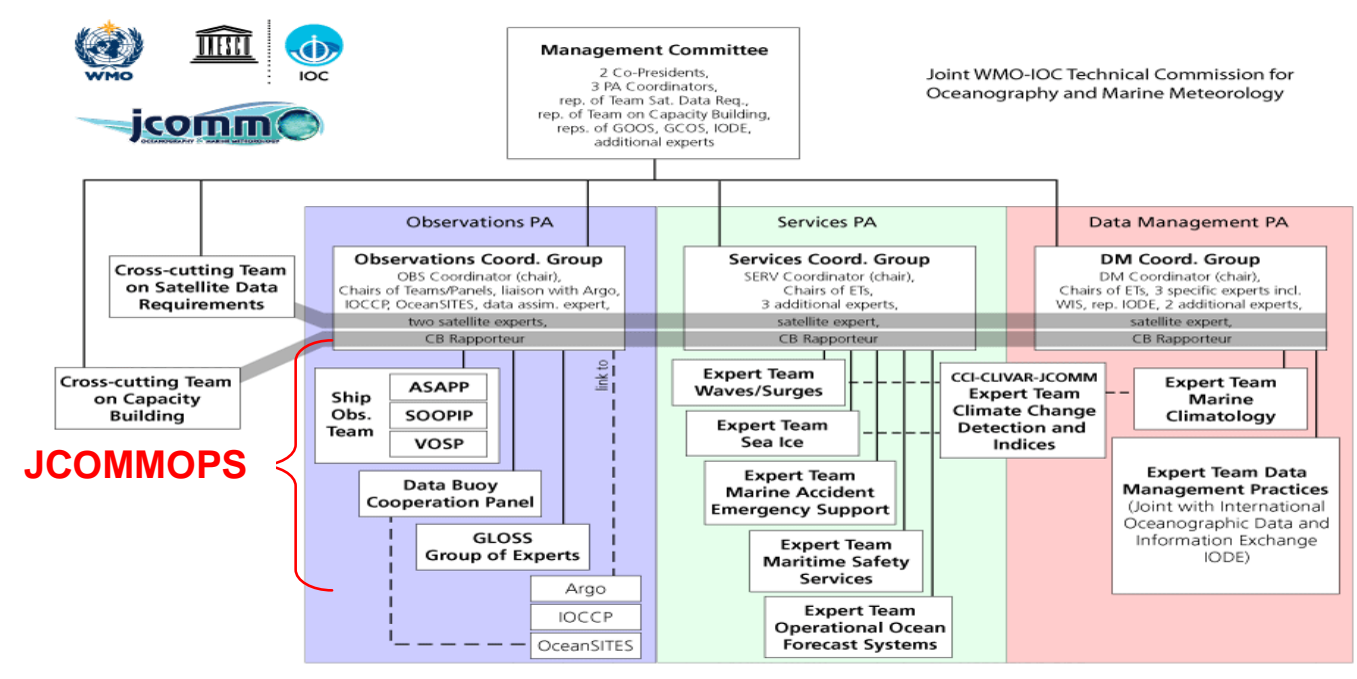

Figure 1: JCOMM Structure. JCOMMOPS is part of the Observations Program Area with links to the Data Management and Services Program Areas.

Feb. 2006 to Jul. 2006

- Etienne Charpentier resigned from DBCP/SOT TC position.

- Transitional period.

- DBCP/SOT TC position vacant.

- May 2006 - JCOMMOPS strategy roundtable discussion with representatives from DBCP, SOT, Argo, OceanSITES, POGO (Partnership for Observation of the Global Oceans), GLOSS (Global Sea Level Observing System), IOCCP (International Ocean Carbon Coordination Program).

Jul. 2006

- Third DBCP/SOT TC recruited (Hester Viola.)

Oct. to Dec. 2007

- Discussions about the expansion of JCOMMOPS to include OceanSITES.

- "Proposal prepared for funding from USA. Informal discussions with SOT, DBCP and Argo Chairs."

Apr. 2008

- DBCP/SOT TC attended the OceanSITES Steering Team meeting and presented the suggested Terms of Reference for the Project Office.
Aug. 2008

- DBCP/SOT TC activities formally extended to support the OceanSITES Project Office.

- Web Developer, Laurent Cros starts working for JCOMMOPS (Half-time)

Feb. 2009 onwards

- Argo TC formally takes up SOT Technical Coordination. DBCP/SOT TC becomes DBCP/OceanSITES TC.

\subsection{Infrastructure}

\subsubsection{Office and Staff}

The JCOMMOPS office is hosted by CLS (Collecte Localisation Satellites) in Toulouse, France. CLS is a satellite-based environmental data collection and location services company. It runs the Argos system, used extensively for ocean observations, on a nonprofit basis. JCOMMOPS is staffed by two full-time technical coordinators (employed by IOC/UNESCO), a half-time I.T. developer (CLS employee), and also occasionally students on work experience.

The IOC and WMO administer dedicated trust funds to manage the global yearly budget for JCOMMOPS, including staff salary and mission budgets, the annual 
logistical contract with its host and all information system maintenance, which is $\sim 250000 €$.

JCOMMOPS is funded through annual (or ad hoc) national voluntary contributions from WMO Members and IOC Member States including Australia, Canada, China, the European Union, France, Germany, India, Japan, New Zealand, South Africa, South Korea, the United Kingdom and the USA. These countries actively participate in the programs, which JCOMMOPS supports, so the work priorities of the Technical Coordinators are, for the most part, set by the steering committee or panel chairs for each program. This means that JCOMMOPS truly represents the international community with complete impartiality.

\subsubsection{The JCOMMOPS Information System}

International programs need centralized and efficient monitoring and communication tools. Information on the programs, platforms and people implementing those networks is constantly changing and needs to be well structured, up to date and easily shared. It must be noted that the primary users of the JCOMMOPS information system are the Technical Coordinators. They use the system for global coordination tasks, including reporting and day to day monitoring and user assistance.

The current Information System is the result of gradual development which began in 2001. While being fully independent within the CLS computing network, the JCOMMOPS information system benefits from the same high performance and operationally supported infrastructure used by CLS to process real-time satellite data and serve its user community. JCOMMOPS is implemented on a three-tier architecture relying on 3 distinct servers (or clusters), for which the hardware and software are regularly updated: a back end database server (Oracle), a middle dynamic content processing application server (Java based) using also GIS (Geographic Information Systems) (ESRI) and chart servers, and a front end web server. JCOMMOPS web services are monitored 24/7.

The JCOMMOPS Information System routinely pulls information from many different sources (e.g.: GTS statistics, Global Data Centres statistics, platforms tracking data from telecommunication systems, quality control information, various metadata entry tools, etc). Platform operators feed the system regularly (e.g. deployment planning, QC feedback). The information is redistributed through different methods (text/XML files, GIS/Google Earth products, on-line tools and database), via the web. This information should permit tracking the status, development, efficiency of the networks but also participates in giving a common interface and visibility to the programs, taking into account their different needs. The web interfaces to JCOMMOPS have not be significantly changed for many years, so have become out-of-date, however the underlying information is still of value to the component programs and across programs.

While a modern information system is a crucial tool, it has little value if it is not developed and maintained by a person to keep a day-to-day link with all platform operators, which is a key task for JCOMMOPS. This is why as well as a support centre, JCOMMOPS could be seen as a "Metadata Management and Quality Control Centre" aiming to assist Data Centres to store and serve more useful information for users and improve global datasets.

\subsubsection{Benefits of a shared infrastructure}

Considering the relatively small number of resources available for coordination or project office activities, sharing a common infrastructure (technical and logistical) is especially necessary. A number of products have been developed across all programs, where the needs are sufficiently similar. In the past, more services and monitoring tools have been developed by the JCOMMOPS centre than would have been possible had the coordinators been working at different locations and using two different information systems. JCOMMOPS has benefitted from twenty years of experience in international and technical coordination. The transfer of expertise and skills that has occurred between the technical coordinators in the past was made possible by the collocation of the staff and their shared systems. Day-to-day communication and knowledge transfer between the coordinators, who deal with similar technical issues, helps them serve their communities better and provide a backup for each other; it also encourages the whole centre to focus on integration of the global observing system components. Over time, this will also ensure continuity and long term support to the programs through preservation of knowledge.

\section{PRODUCTS AND SERVICES}

The first service provided by JCOMMOPS to all programs is a dedicated human resource: the Technical Coordinator. They are a focal point, supporting the program and the people responsible for each national or regional contribution, on a wide range of issues which can be grouped into broad areas of: Assistance, Monitoring and Cooperation.

The coordinators monitor and provide oversight for the implementation of the global array, and understand all of the elements of the global system including platforms, people, data systems and unique international/national/regional/institutional considerations. 
Grouped into these categories, JCOMMOPS fulfils its terms of reference by providing services such as:

\subsection{Assistance}

- Assistance on any issue required to participate in an international program.

- Assistance to national programs and individual platform operators, scientists or data users.

- Assistance in data distribution, following appropriate standards.

- Assistance with information about platform manufacturers and telecommunication systems providers.

- Assistance in logistics (deployment planning, deployment methods, instrument retrieval).

- A web portal to find information relating to ocean observing systems, including a centralized source of documentation, contact details, program information and platforms, contacts, etc...

- A common system for managing communications (e.g. news items, mailing lists, picture galleries, etc).

- Enhanced user support - e.g. direct contact with program managers, platform operators and data users.

- Assistance to the community or media (photos, maps, articles, presentations, etc).

2.2 Monitoring Services (see Figures 2 - 6):

- An authoritative source of metadata for platforms and official status of the arrays.

- Real-time web applications to browse the platform database.

- Real-time GIS/Chart based monitoring and tracking tools aimed at:

- Providing statistics to program managers who are interested in the progress of the implementation of all programs;

- ensuring that data is available for use via the correct means and that data providers are supported in sharing their data.

- Daily Metadata export files (Textual, XML, Google Earth outputs).

- Common and integrated monitoring tools across the networks.

- Common and specific performance evaluation tools for the networks.

- Integration of quality control feedback mechanisms across programs.
- Centralized deployment planning tools.

- Capacity for shared deployment opportunities

- Management of metadata quality and completeness.

- Detection of problems with data formats, data archives etc in global datasets.

- Various monthly and yearly products and reports.

\subsection{Cooperation}

- Encouraging standardization and harmonization of Data Formats and Table driven code forms.

- Encouraging cooperation between research and operational communities within the domains of oceanography and meteorology.

- Encouraging international cooperation through multilateral and cross-program initiatives (e.g. training sessions on floats/buoys/XBTs related practices, proactive development of international cooperation through Platform Donor Programs).

\section{COMMENTS FROM THE JCOMM SECRETARIAT AND COMPONENT PANELS ABOUT JCOMMOPS}

\subsection{Comments from JCOMM Co-president/s on the evolution of centre:}

"A support centre for the implementation of all observing programs will be essential to enable the sustained deployment of an ocean observing system over the next 5-10 years, and JCOMMOPS forms the basis of this evolution."

\subsection{Extract from 60th session of the WMO} Executive Council:

(...) As regards the development of an ocean Observing Programs Support Centre (OPSC) in cooperation with $I O C$, and as an expansion of the existing successful JCOMM in situ Observing Platform Support (JCOMMOPS) centre that contributed towards developing components of an integrated composite ocean observing system, the Council requested Members to commit resources through voluntary contributions to support the implementation and operations of the Centre.(...).

\subsection{Extract from 41st session of the IOC/UNESCO Executive Council:}

(...) Progress has been made on the establishment of an Observing Program Support Centre, building on the existing highly regarded JCOMMOPS. (...) 
Member States supported the ongoing work on the creation of an Observation Program Support Centre (OPSC), so as to expand on the success of JCOMMOPS (...).

\subsection{Extract from IOC/UNESCO Resolution EC-XLI.4:}

(...) Acknowledging the work of the Argo Information Centre to facilitate the deployment of Argo profiling floats, to inform Member States, as appropriate, of planned and actual deployments, and to facilitate dissemination of identification and location of deployments and float data, (...)

\subsection{Comments from the DBCP Chair:}

"The DBCP has relied upon its technical coordinator for over 20 years and has succeeded in implementing its optimal network and sustaining that level, with

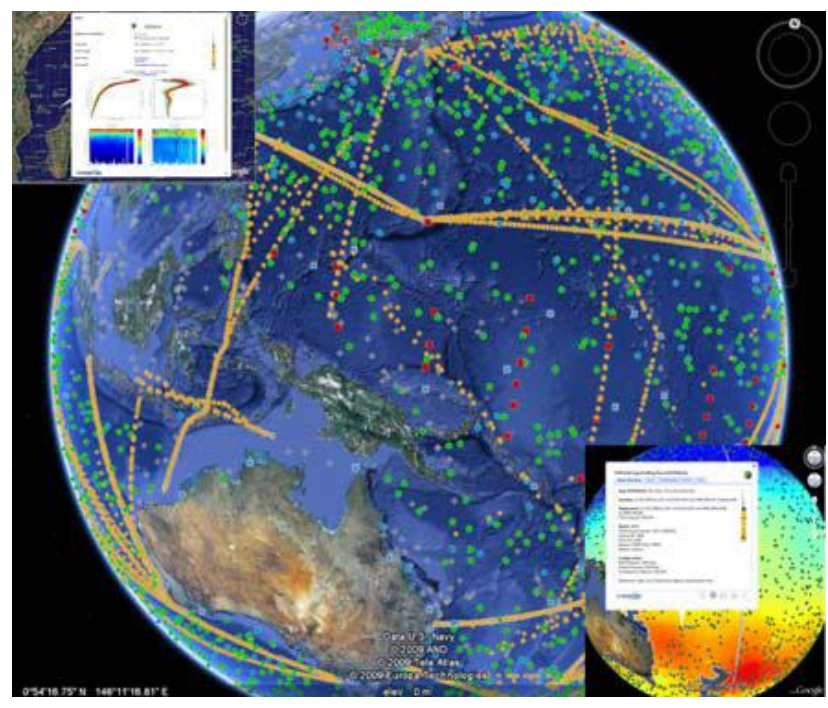

Figure 2: Very early on, JCOMMOPS provided online GIS-based, real-time tracking tools for ocean platforms and is now working on a partnership with Google to include JCOMM/GOOS observing systems status and products under Google Ocean.
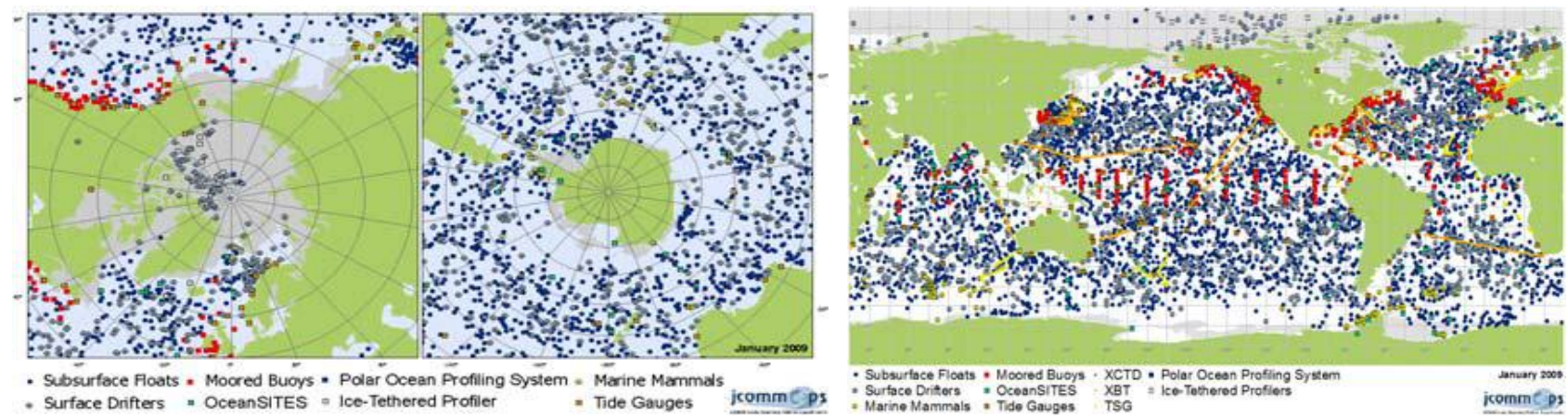

Figure 3: Platforms reporting during January 2009 across most of JCOMM programs (standard JCOMM Global view and Polar views) 

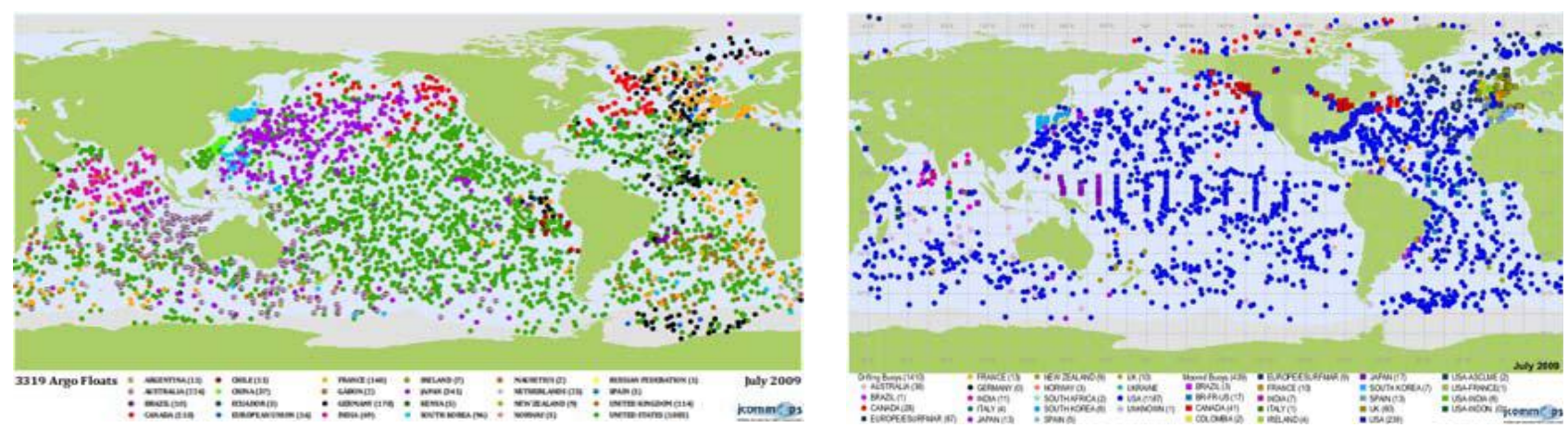

Figure 4: Argo and DBCP status maps by country. They provide an up to date and official status of the arrays but also encourage the community to share data. Countries with observing programs have to share data and metadata as appropriate in order to appear on these maps.
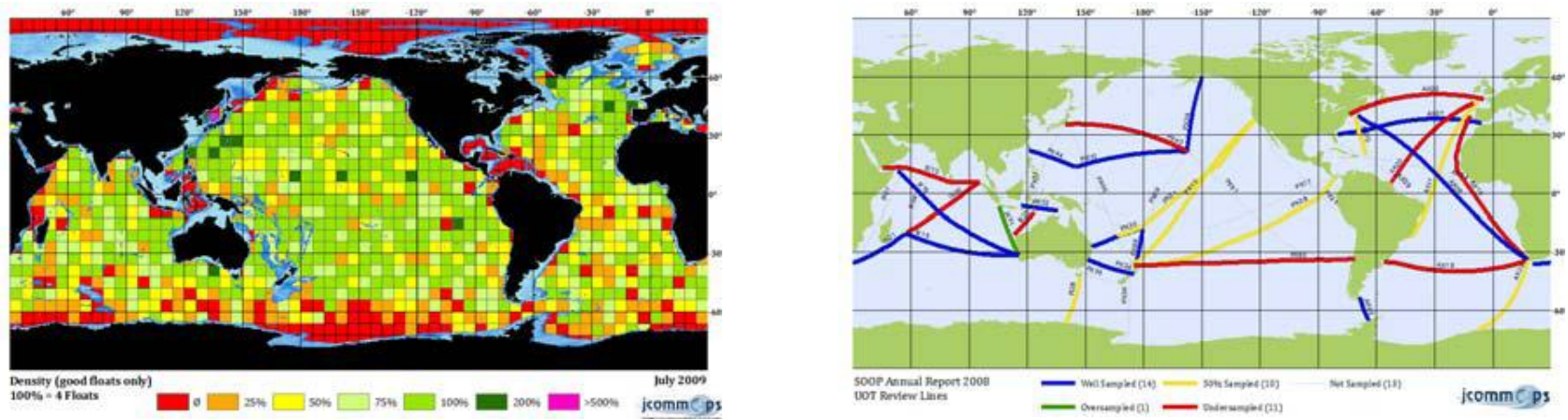

Figure 5: Sample products showing how the programs assess and meet their requirements: left) Argo Network Density on a $6^{\circ} \times 6^{\circ}$ grid normalized on the $3^{\circ} \times 3^{\circ}$ Argo standard (100\% means here 4 floats operating in a box), right) Results of analysis for January to December 2008 along only Upper Ocean Thermal Review SOOP Lines
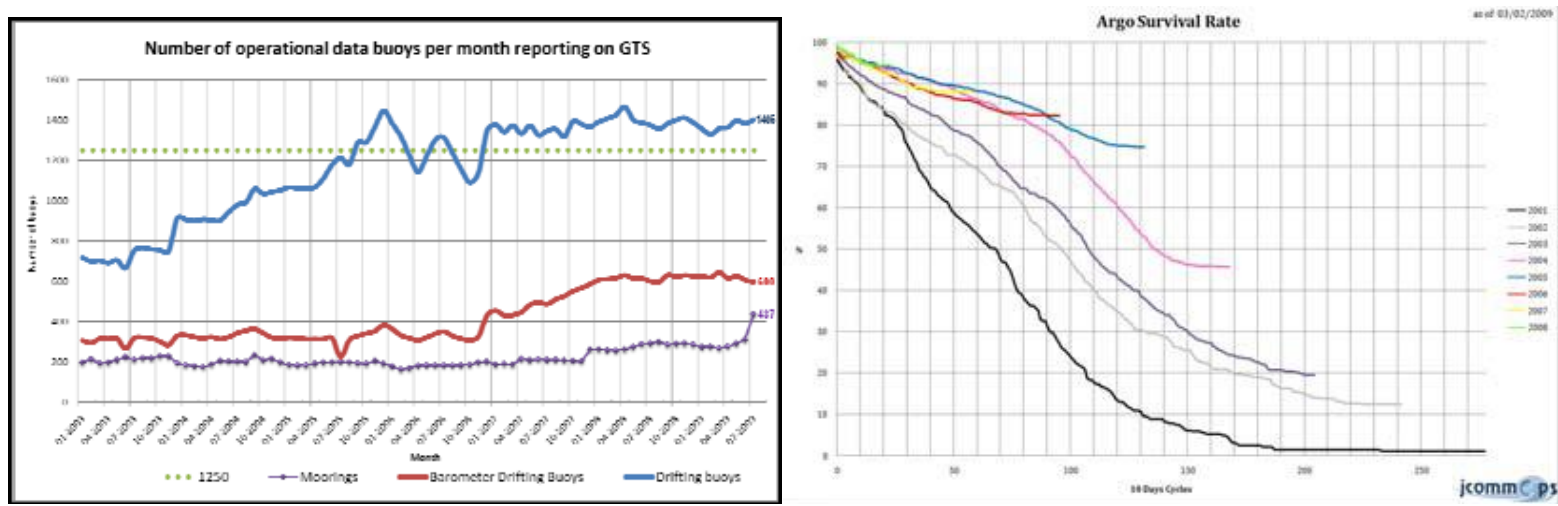

Figure 6: left) Sample products measuring the growth and efficiency of the arrays.

Monthly evolution of the number of operational drifting and moored buoys reporting on GTS from March 2003 to December 2009 (including those reporting air pressures). right) Argo Survival Rate. Profiling float technology has dramatically improved in the last few years thank to the expertises developed within Argo. 
quality assured data being shared freely and openly. The JCOMMOPS centre allows the DBCP to centralise its program information management and share the technology infrastructure for the collection and exchange of buoy instrument metadata, with other programs. It is in a good position to provide assistance to data providers and users, with operational issues, data flow, data management and telecommunications. With this in mind, the DBCP has always encouraged the further development and expansion of JCOMMOPS, so that other panels and steering teams can benefit from having a focal point and a centre for technical coordination, in order to move together as a community towards greater standardisation, development of common practices, as well as better sharing of common technical and operational resources."

\subsection{Comments Argo Steering Team Co-Chairs:}

"Argo would not be possible without having coordination both at scientific and technical levels. The Argo Information Center carries out a number of essential technical coordination functions including formal notification of float deployment as mandated by IOC Resolution XX-6, public distribution of deployment plans for information and coordination, tracking and distribution of location and statistical data concerning the Argo array, communications support for recovering beached floats, serving as a clearinghouse for documents, and facilitating communications among Argo partners and with the Argo user community., In other words, Argo can strongly underline the importance of the AIC to Argo implementation. The value of JCOMMOPS for coordinating across observing system elements is still a work in progress."

\subsection{Comments from the OceanSITES Steering Team Co-Chairs:}

The OceanSITES Project Office benefits from being based in JCOMMOPS, rather than in a national organization, as it provides a truly international focus and neutral representation for the program.

\section{FUTURE OF JCOMMOPS}

In the last three years JCOMM has undergone an assessment of the needs and explored the various options for expanding JCOMMOPS activities into an integrated JCOMM Observing Program Support Centre.

At the same time, is it widely recognized that in order to fully implement a sustained global ocean observing system, an expanded technical support centre is essential to serving the growing requirements of the
DBCP, SOT, and AST (Argo Steering Team), and in addition begin to serve the developing requirements of other international programs, also working to coordinate elements of the global ocean observing system.

Following informal discussions with potential hosts a Joint Circular Letter to the member states of IOC and the permanent representatives of members of WMO was prepared. The letter explained the background and justification for an expanded JCOMMOPS and solicited a letter of intent from prospective hosts, stating how they met the requirements set out.

Thirteen (13) Member States submitted proposals to host the Support Centre.

Five (5) proposals were short listed, and the final decision was announced in October 2009 by the Secretary-General of WMO, and the Executive Secretary of IOC, based on the recommendations from the Evaluation Committee (JCOMM co-presidents, representative of AST, DBCP, SOT, OceanSITES, IOCCP, GLOSS, WIGOS (WMO Integrated Global Observing System), OOPC (Ocean Observations Panel for Climate), IOC and WMO secretariat). The French proposal, supported by CLS and Ifremer was ranked first and accepted. IOC and WMO "thank CLS and Ifremerx, as well as France for their offer which will contribute substantially towards the implementation and operations of ocean observing systems in support of WMO and IOC Programmes".

The "expanded JCOMMOPS" will do much to rationalize and optimize the national contributions of the several Members/Member States that are working to cooperatively implement the global ocean observing system.

The envisioned Support Centre will promote integration across elements of the in situ observing system, as well as provide sustained support to the individual components. The JCOMMOPS centre has evolved over its lifetime as the information system, which underpins it, has become more complete and the programs are able to work more closely together on fulfilling common informational and programmatic goals. It is clear that a dynamic centre, with a high profile (both on the web and as a focal point for technical issues), is a key element in demonstrating - to the contributing Members/Members States, existing and future - the benefit and value of sustained ocean observations. Such a centre would also assist in the cross-JCOMM coordination of the observation requirements from the Data Management and Services Program Areas, as well as coordination across the international science programs working to help 
implement a global ocean observing system. Such a structure will be flexible enough to take into account the different needs of each program e.g. some will need operational support while others will need support for research activities or help demonstrating the value of the observing system.

In addition, as part of the expanded JCOMMOPS, there is a need to improve coordination between satellite and in situ data systems. There may be a role for maintaining information about satellite data requirements, future plans, the satellite data products, as well as enhancing the dialogue between in situ platform operators and those who provide satellite products (for example to permit provision of quality information back to in situ platform operators).

In parallel to the process undertaken for developing the Support Centre, JCOMMOPS has progressed on expanding its scope to incorporate OceanSITES project office support. JCOMMOPS has also assisted a number of emerging programs: such as observing programs from Marine Mammals (MEOP (Marine Mammal Exploration of the Oceans - Pole to Pole)), Bio-Argo, and Ice-Tethered Profilers, gliders. These new elements of the JCOMM/GOOS, plus others, such as the International Tsunami network would gain significantly and quickly by joining and strengthening the existing infrastructure built up over the last decade. , In term of observations, JCOMMOPS has a good deal of experience in oceanography, marine meteorology, however more expertise in biology and "green operational oceanography" would be welcome.

\section{CHALLENGES FOR THE NEXT DECADE}

\subsection{Strengthen the existing infrastructure}

JCOMMOPS requires a more stable financial base to allow it to grow and develop. The Observing Panels supporting JCOMMOPS will keep seeking new national contributions but this will allow only continuing at the current staffing level. At a minimum JCOMMOPS would like to accrue enough additional funding from International or Regional Organisations to ensure that the half time Web Developer position can be converted into a full time position in 2010 and maintained in future. Also JCOMMOPS hosts have strengthened their support by offering a quarter-time senior scientist position to help the centre to promote the existing programmes, expand its services to new ocean observing programmes, bring the research oriented expertise and allow more interactions with research communities. Additionally, JCOMMOPS has identified the need for international and technical coordination around all ship/cruise related activities across programs in order to:

- Facilitate maintenance and operations of global arrays through logistics coordination when required.

- Further develop cooperation between programs (e.g. shared cruises, ship time).

- Further develop Float/buoy donor programs and identify new regional deployment opportunities.

- Arrange retrieval of beached instruments when necessary.

- Identify future research cruises, and CTD (Conductivity-Temperature-Depth) data essential to Argo data quality control, in cooperation with the GOSHIP (Global Ocean Ship-based Hydrographic Investigations Program), CCHDO (CLIVAR and Carbon Hydrographic Data Office) and POGO initiatives.

If resources could be allocated to such a position, all programs would benefit and be more easily sustainable in the future.

On the other hand, in its Community White Paper GOSHIP identifies the need for continued coordination, including information and communication management, data issues, implementation issues, international issues, cooperation with other programmes, etc. This is typically what a GO-SHIP Coordinator could do within JCOMMOPS.

The combination of those requirements demonstrates the need for a new dedicated and full time resource, that would be the focal point for all ship based information.

\subsection{Design a new generation of integrated web services}

The JCOMMOPS information system is a good data bank of platform, instrument and related metadata. The challenge faced by JCOMMOPS has been, and continues to be, how to present this information in the best way to those who require it. One of the main difficulties is that JCOMMOPS web services target many different user communities: program managers, researchers, technical groups, operational teams, data managers, etc. 
JCOMMOPS aims to clarify access to information and develop a web based toolbox that will be used for many years to come.

These issues are being addressed by:

- integrating the technical elements of the Information System better;

- designing a new structure for the JCOMMOPS website;

- analysing, in depth, the results of the websites audience tracking set up a year ago;

- using more interactivity in navigation (thanks to new technologies);

- developing a profile based service: " $M y$ JCOMMOPS".

\section{CONCLUSION}

The number of responses to JCOMM's request for hosting an expanded Support Centre demonstrates that JCOMMOPS is well supported by the IOC Member States and WMO Members. There are potentially many opportunities for growth and for acquiring the extra resources necessary.

JCOMMOPS is open to all extensions and changes in its operations, and will be pleased to assist other communities in-charge of implementing global ocean observing systems.

International programs develop through national contributions, with various fields of expertise and various people involved, which can be linked through the data being collected and the information available about the program. Any complex system needs some human intervention to be as comprehensive and efficient as possible. The JCOMMOPS technical coordinators act to smooth over issues and provide a focal point for this "system of systems". While there is a lot of debate on the path for observing programs moving from research and development through to operational status, JCOMMOPS, based on its experience, advocates a new hybrid model, promoting the continuous cooperation between research and operational partners.

The components of the Global Ocean Observing System recognize that they need to work together to ensure the networks can be maintained in future, especially as resources allocated to Global Ocean Observations are insufficient today. Even a relatively ground breaking program such as Argo is still underfunded (mostly through research money), after having already demonstrated its benefits. As a result, resources allocated to the coordination and information infrastructures of such programs do not reflect the value that could be brought by including more programs under JCOMMOPS with dedicated resources focused on particular networks.

This white paper offers the opportunity to the broad Ocean Observations community to benefit from and increase capabilities of the existing JCOMMOPS Centre.

\section{REFERENCES}

\subsection{Background documents}

- JCOMMOPS background and status (E. Charpentier, M. Belbeoch)

- JCOMM II Report

\subsection{Key websites}

- http://www.jcommops.org (JCOMMOPS)

- http://argo.jcommops.org (Argo Information Centre)

- http://dbcp.jcommops.org (Data Buoy Cooperation Panel)

- http://sot.jcommops.org (Ship Observation Team)

- http://www.oceansites.org(OceanSITES)

- http://www.jcomm.info (JCOMM)

8.3 Monitoring tools examples

- JCOMMOPS Interactive Map

\subsection{Specific Reports}

- Argo

- Monthly Maps

- $\quad$ Interactive Map

- $\quad \underline{\text { Argo Google Earth }}$ Argo Google Earth II

- $\quad$ Argo Planning

- $\quad$ Argo Data Distribution Status

- Argo Information Centre monthly report

- Argo Text/GIS files export

- DBCP Monthly Maps and Google Earth http://www.jcommops.org/dbcp/network/maps

- $\quad$ SOOP Annual Survey

- OceanSITES http://www.oceansites.org 